\title{
Contact stress analysis of steel and composite spur gear pairs
}

\author{
Bharat N. Bakshe ${ }^{1 *}$ and S. R. Patil ${ }^{2}$ \\ PG Student, Department of Mechanical Engineering, AISSMS COE, SSPU, Pune, India ${ }^{1}$ \\ Assistant Professor, Department of Mechanical Engineering, AISSMS COE, SSPU, Pune, India ${ }^{2}$
}

(C2018 ACCENTS

\begin{abstract}
Gears are one of the most critical components in a mechanical power transmission system and in most rotating machinery. Gear teeth usually fail due to increase in load above certain limit. Therefore, it is required to use different materials for gear manufacturing. Metal matrix composites possess improved properties including high strength, high stiffness, and reduction in weight, compared with unreinforced alloy. The objective of this work is concerned with replacing metallic gear with gear of composite material of aluminium silicon carbide and fly ash so as to improve performance of machines and to have longer working life. Aluminium alloy, SiC and fly ash are used as matrix and reinforcing material. Contact stress is the key parameter in mating gear in gear design. This work represents contact stress analysis of steel and composite gear pairs using hertz theory and finite element analysis (FEA) using ANSYS. In this work, aluminium silicon carbide and fly ash is used as a gear material. Also experimental stresses are calculated using strain gauge technique. When compared, the results of both theoretical method and FEA show a good degree of agreement with experimental results. It is observed that stresses are nearly reduced by $18 \%$ by the use of composite material. Also the weight of composite material is nearly 3 times less than steel material. So the composites can be used for making power transmitting elements such as gears, which are subjected to continuous loading.
\end{abstract}

\section{Keywords}

Contact stress, Hertz equation, Spur gear, Composite gear, ANSYS 16.0, Strain gauge.

\section{Introduction}

Aluminium alloy materials or simply metal matrix composites are combinations of materials. Composites are made up of combining two or more materials in such a way that the resulting materials have certain design properties or improved properties. Aluminium alloy composite materials are mostly used for a many number of applications such as engineering structures, electronic applications, sporting goods as they are less in weight with better properties [1].

Gears are the most common method of transmitting power in mechanical engineering. With the moving wheel of science and technology the use of gears has become preferably common in almost all the upcoming industries. The spur gear are simple in design, manufactured economically, requires less maintenance. Fly ash, borax powder or magnesium is added to improve the properties [2]. In present work the main objective is to replace metallic gear with gear of composite material of aluminium silicon carbide and fly ash so as to improve performance of machine and to have longer working life.

*Author for correspondence

262
The objectives of this paper are as follows:

1. To design and analyze the gear using computeraided design (CAD) and computer-aided engineering (CAE) software.

2. To increase the contact strength of spur gear using composite material.

3. To determine the contact stress by using strain gauge setup.

\section{Literature review}

Pawar and Utpat [1] have developed a metal matrix composite of aluminium based silicon carbide. Authors has done FEA of gear using ANSYS 14.0 and concluded that composite gears offer improved properties over steel alloys and can be replaced with metallic gears [2]. Saravanan and Kumar[3] has developed metal matrix composites by varying rice husk ash percentage and concludes that with increase in percentage of rice husk ash in metal matrix composites will increase ultimate tensile strength, compressive strength and hardness of the composite. Devi et al. [4] conducted experiments for tensile strength by varying mass fraction of $\mathrm{SiC}$ with aluminium and found that aluminium silicon carbide composite material is having less weight and more 
strength. Suragimath and Purohit [5] conducted experiment by varying fly ash weight fraction with constant $\mathrm{SiC}$ and found that the increase in addition of fly ash increases the tensile strength, impact strength, wear resistance of the specimen and decreases the percentage of elongation.

Hassan [6] considered different contact positions for contact stress analysis between two spur gear teeth, representing a pair of mating gears during rotation and developed a programme to plot a pair of teeth in contact. Hwang et al. [7] presents a contact stress analysis for a pair of mating gears during rotation and performed contact stress analysis for spur and helical gears between two gear teeth at different contact positions during rotation.

Tiwari and Joshi [8] presented analysis of bending stress and contact stress of involute spur gear teeth and found that hertz theory is the basis of contact stress calculation. Theoretical results which are obtained from Lewis formula and Hertz equation are comparable with FEA results. Khan and Mangla [9] analysed contact stress of spur gears by theoretical method using Hertz equations and by FEA using ANSYS 14.0 workbench. The spur gear is sketched, modelled and analysed using ANSYS. It is found that the results obtained from theoretical method and FEA are comparable with each other.

Quadri and Dhananjay [10] Analysed spur gear pair for contact stress analysis which is under static loading conditions. The results obtained for contact stresses using Hertz theory and FEA are compared. Kolambe and Barde [11] analysed helical gear using FEA. To calculate the bending stress, 3D solid models for different number of teeth are generated by using CATIA and the numerical analysis is done by FEA using ANSYS. The Lewis stress formula is used for analytical investigation. The stresses found by using ANSYS are compared with results obtained from theoretical and AGMA values. Rahate and
Marne [12] conducted FEA for contact stress analysis on composite spur gear pair and found that stress is reduced due to use of composite gear.

Patil et al. [13] studied contact stress in gears. Gear dynamic stress test rig (GDSTR) is used for experimental testing and analysis of the helical gear. The strain gauge and carbon slip rings are used in GDSTR to measure the surface contact stresses at the contacting points of a meshed gears. Jebur et al. [14] investigates the characteristics of an Involute gear system including contact stresses between pair of the gears for $3 \mathrm{D}$ and comparing the results with the experimental results. The experimental analysis established in new idea by using the D.C servomotor and planting the strain gauges in the tooth of the gear. Chor and Pillai [15] studied gear by increasing the module of gear to reduce contact stress. One spur gear train is selected for analysis. The contact stress of already existing gear train is determined and compared with fatigue strengths of gear material. If these calculated stresses on gears are higher than fatigue strengths then it means gears are failed due to fatigue. The contact stress is calculated by using Hertz's equation and the experimental investigation of the stress field is done by using strain gauge technique.

\section{Material properties and design parameters}

For investigation, $\mathrm{Al}, \mathrm{SiC}(12 \%)$, fly ash (15\%) is used as a matrix material. The material properties of steel and aluminium silicon carbide composite are given in the Table 1 .

The basic design of spur gear is same for both the gears as the comparative study of steel gear and composite gear is done. The various parameters of gear design are given in the Table 2.

Table 1 Material property of gears

\begin{tabular}{lll}
\hline Material properties & Steel & AlSiC + FA \\
\hline Young's modulus & $200 \mathrm{GPa}$ & $134 \mathrm{GPa}$ \\
Poisson's ratio & 0.3 & 0.29 \\
Ultimate tensile strength & $841 \mathrm{~N} / \mathrm{mm}^{2}$ & $402 \mathrm{~N} / \mathrm{mm}^{2}$ \\
Density & $7850 \mathrm{Kg} / \mathrm{m}^{3}$ & $2580 \mathrm{Kg} / \mathrm{m}^{3}$ \\
\hline
\end{tabular}

Table 2 Design parameters of gears

\begin{tabular}{ll}
\hline Parameters & Value \\
\hline No. of teeth & 20 \\
Module & $4.5 \mathrm{~mm}$ \\
\hline
\end{tabular}


Bakshe et al.

\begin{tabular}{ll}
\hline Parameters & Value \\
\hline Gear ratio & 1 \\
Pressure angle & $20^{0}$ \\
Face width & $30 \mathrm{~mm}$ \\
Center distance & $90 \mathrm{~mm}$ \\
Pitch diameter & $90 \mathrm{~mm}$ \\
Torque & $150 \mathrm{~m}$ \\
\hline
\end{tabular}

\section{Theoretical contact stress analysis using hertz theory}

Earle Buckingham have used hertz theory to calculate contact stresses between rotating pair of teeth in 1926 by considering external cylindrical spur gears as two parallel cylinders in contact with radiuses of curvature. When two cylinders are pressed together then the contact stress is given by [16],

$\sigma_{c}=\frac{2 \mathrm{P}}{\pi \mathrm{BL}}$

Where,

$$
B=\left[\frac{2 P\left(\frac{1-\mu_{1}{ }^{2}}{E_{1}}+\frac{1-\mu_{2}{ }^{2}}{E_{2}}\right)}{\pi L\left(\frac{1}{d_{1}}+\frac{1}{d_{2}}\right)}\right]^{1 / 2}
$$

$\sigma_{\mathrm{c}}=$ maximum value of contact stress in $\mathrm{N} / \mathrm{mm}^{2}$

$\mathrm{P} \quad=$ force pressing the two cylinders together in $\mathrm{N}$

$\mathrm{B}=$ half width of deformation in $\mathrm{mm}$

$\mathrm{L} \quad=$ axial length of cylinders in $\mathrm{mm}$

$\mathrm{d}_{1}, \mathrm{~d}_{2}=$ diameters of two cylinders in $\mathrm{mm}$

$\mathrm{E}_{1}, \mathrm{E}_{2}=$ modulii of elasticity of two cylinder materials in $\mathrm{N} / \mathrm{mm}^{2}$

$\mu_{1}, \mu_{2}=$ Poisson's ratio of the two cylinder materials Substituting value of half width of deformation, B in equation (1) and squaring both sides,

$$
=\frac{1}{\pi}\left(\frac{P}{L}\right)\left[\frac{\left(\frac{1}{r_{1}}+\frac{1}{r_{2}}\right)}{\left(\frac{1-\mu_{1}^{2}}{E_{1}}+\frac{1-\mu_{2}{ }^{2}}{E_{2}}\right)}\right]
$$

If it is assumed that the material of both the cylinders is same, then the modulus of elasticity and Poisson's ratio will be same. Therefore, substituting $\mathrm{E}_{1}=\mathrm{E}_{2}=\mathrm{E}$ and $\mu_{1}=\mu_{2}=\mu$ in equation (4),

$\sigma_{c}^{2}=\frac{1}{2 \pi}\left(\frac{P}{L}\right)\left[\frac{\left(\frac{1}{r_{1}}+\frac{1}{r_{2}}\right)}{\left(\frac{1-\mu^{2}}{E}\right)}\right]$
Now, to apply this equation to a pair of spur gear teeth in contact, it is necessary to replace the radii $r_{l}$ and $r_{2}$ by the radii of curvature at the pitch point,

$r_{1}=\frac{d_{p p} \sin \phi}{2}$ and $r_{2}=\frac{d_{p g} \sin \phi}{2}$

Now, since the pinion and gear are of equal geometry as given in Table 2, then

$d_{p p}=d_{p g}=d_{p}$

$r_{1}=r_{2}=r=\frac{d_{p} \sin \phi}{2}$

From equation (4) and (5),

$\sigma_{c}^{2}=\frac{1}{\pi\left(1-\mu^{2}\right)}\left(\frac{P E}{L r}\right)$

now,

$r=r_{p} \sin \phi$ and $P=\frac{P_{t}}{\cos \phi}$

The tangential force acting on the tooth can be calculated by,

$P_{t}=\frac{2 T}{d_{p}}$

The length $L$ and face width $b$ of spur gears are considered as same, therefore replacing $L$ by $b$ in equation (6). Then the equation is obtained as,

$\sigma_{c}=\left[\frac{1}{\pi\left(1-\mu^{2}\right)}\left(\frac{P_{t} E}{b r_{p} \sin \phi \cos \phi}\right)\right]^{1 / 2}$

By using equation (7) theoretical contact stress can be calculated.

Table 3 shows theoretical contact stresses in steel and composite gear using Hertz equation.

Table 3 Theoretical data for contact stress in steel and composite gear using Hertz equation

\begin{tabular}{cccc}
\hline Torque (N.m) & Tangential force $(\mathbf{N})$ & $\begin{array}{c}\text { Contact stress in steel gears } \\
(\mathbf{M P a})\end{array}$ & $\begin{array}{c}\text { Contact stress in composite gears } \\
(\mathbf{M P a})\end{array}$ \\
\hline 50 & 1111.11 & 423.26 & 345.34 \\
100 & 2222.22 & 598.59 & 488.38 \\
150 & 3333.33 & 733.12 & 598.14 \\
\hline
\end{tabular}




\section{Numerical analysis using FEA}

In the present study, FEA software ANSYS 16.0 workbench has been used for numerical analysis to calculate the maximum allowable contact stress in steel and composite spur gears. The gear is modelled in CREO 3.0 and imported in ANSYS as STP file for analysis. Fine meshing has been done as shown in Figure 1, in order to get good results. Fixed support is applied on inner rim of the gear. Frictionless support is applied on the inner rim of other gear to allow its tangential rotation [17]. A moment of 150 N.m is applied in clockwise direction on the inner rim of the gear as shown in Figure 2.

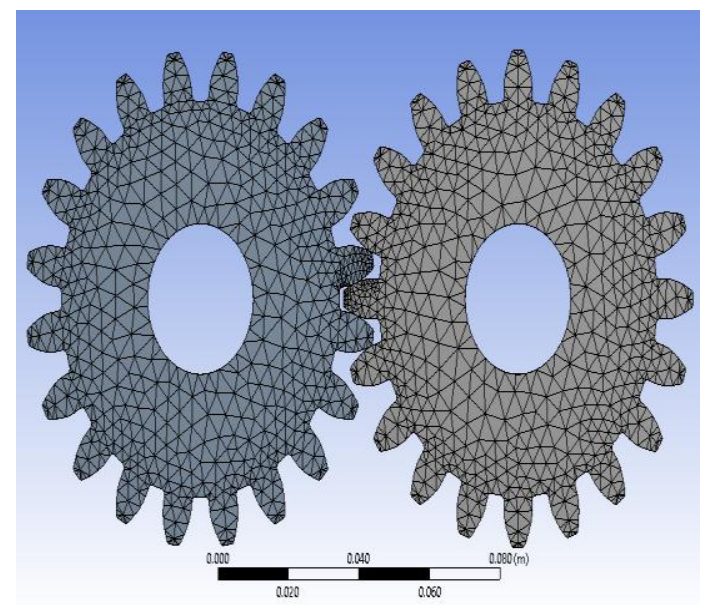

Figure 1 Meshed model

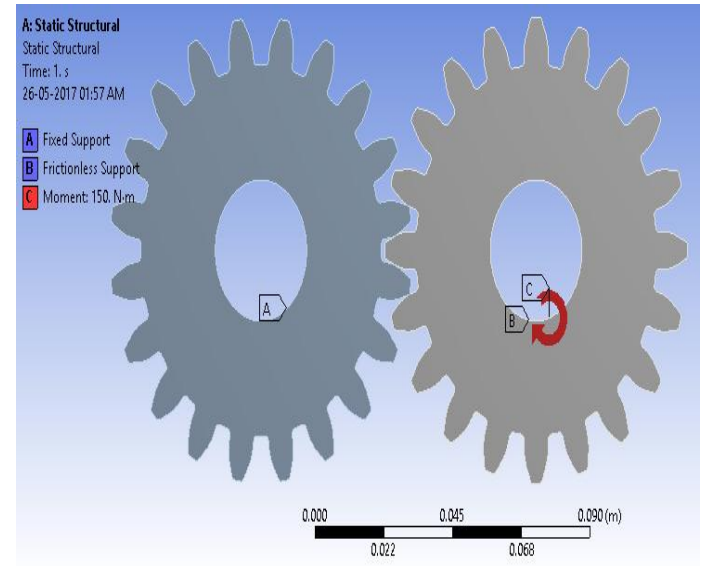

Figure 2 Boundary conditions
Figure 3 shows the maximum contact stress obtained for steel gear pair for 150 N.m torque. The finite element analysis is done by using ANSYS.

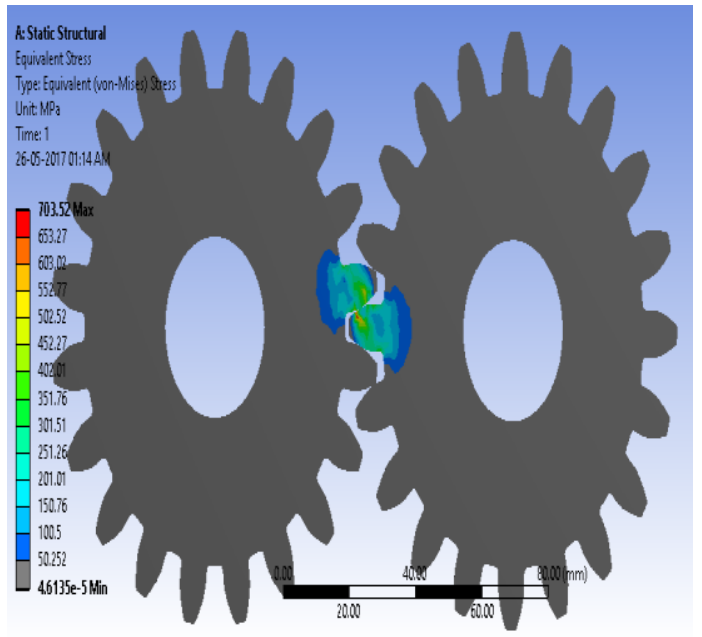

Figure 3 Contact stress of steel gear pair for 150 N.m torque

Figure 4 shows the maximum contact stress obtained for composite gear pair for 150 N.m torque. The finite element analysis is done by using ANSYS.

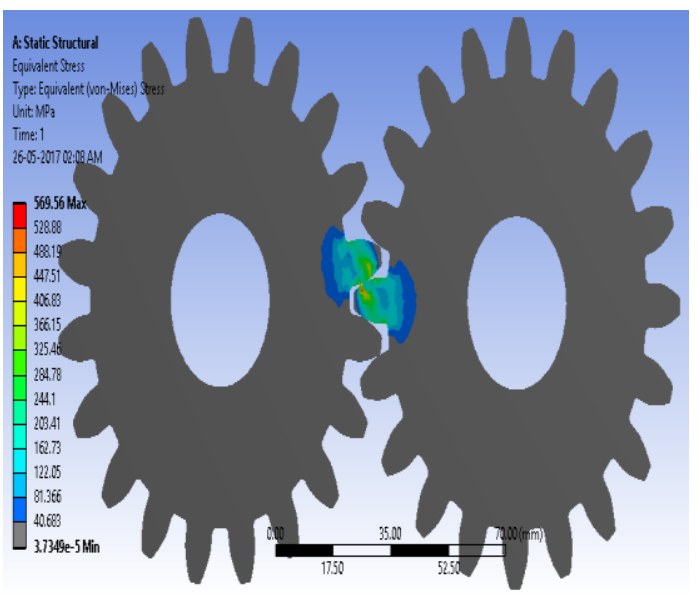

Figure 4 Contact stress of composite gear pair for 150 N.m torque

Table 4 shows contact stresses calculated using FEM for steel and composite gear.

Table 4 FEM data for contact stress in steel and composite gear

\begin{tabular}{lccl}
\hline Torque (N.m) & Tangential force $(\mathbf{N})$ & $\begin{array}{l}\text { Contact stress in steel gears } \\
(\mathbf{M P a})\end{array}$ & $\begin{array}{l}\text { Contact stress in composite gears } \\
(\mathbf{M P a})\end{array}$ \\
\hline 50 & 1111.11 & 398.70 & 331.23 \\
100 & 2222.22 & 564.32 & 460.04 \\
150 & 3333.33 & 703.52 & 569.56 \\
\hline
\end{tabular}


Bakshe et al.

\section{Experimental stress analysis using strain gauge technique}

The experimental stress analysis is carried out by using strain gauge technique. Strain gauges are planted on the gear tooth faces. Strain gauges with Wheatstone bridge circuit are used to find strain values. By using experimental strain, stresses can be calculated.

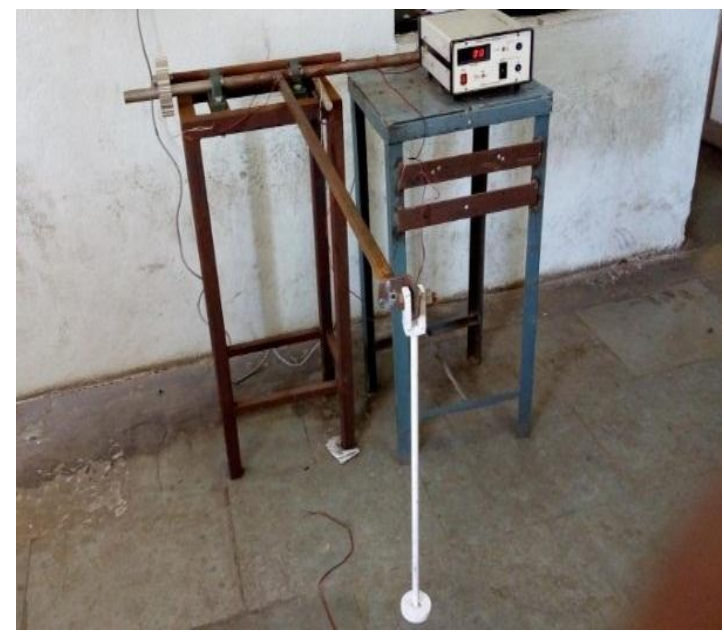

Figure 5 Loading arrangement of gear pair
Table 5 and Table 6 shows contact stresses calculated using experimental strain gauge technique.

Table 5 Experimental data for pair of steel gear

\begin{tabular}{lllll}
\hline $\begin{array}{l}\text { Load } \\
(\mathbf{K g})\end{array}$ & $\begin{array}{l}\text { Torque } \\
(\mathbf{N . m})\end{array}$ & $\begin{array}{l}\text { Tangential } \\
\text { force }(\mathbf{N})\end{array}$ & $\begin{array}{l}\text { Experimental } \\
\text { strain }(\boldsymbol{\mu e})\end{array}$ & $\begin{array}{l}\text { Contact } \\
\text { stress } \\
(\mathbf{M P a})\end{array}$ \\
\hline 5 & 50 & 1111.11 & 0.002260 & 452.12 \\
10 & 100 & 2222.22 & 0.003239 & 647.85 \\
15 & 150 & 3333.33 & 0.004 & 800 \\
\hline
\end{tabular}

Table 6 Experimental data for pair of composite gear

\begin{tabular}{lllll}
\hline $\begin{array}{l}\text { Load } \\
(\mathbf{K g})\end{array}$ & $\begin{array}{l}\text { Torque } \\
(\mathbf{N} . \mathbf{m})\end{array}$ & $\begin{array}{l}\text { Tangential } \\
\text { force }(\mathbf{N})\end{array}$ & $\begin{array}{l}\text { Experimental } \\
\text { strain }(\boldsymbol{\mu e})\end{array}$ & $\begin{array}{l}\text { Contact } \\
\text { stress } \\
(\mathbf{M P a})\end{array}$ \\
\hline 5 & 50 & 1111.11 & 0.002792 & 374.34 \\
10 & 100 & 2222.22 & 0.004 & 536 \\
15 & 150 & 3333.33 & 0.004872 & 652.87 \\
\hline
\end{tabular}

\section{Result and discussion}

In this work, the contact stresses in the gears are calculated by Hertz theory and FEM. It is validated by conducting the experiment using strain gauge technique. Figure 6 and Figure 7 shows the comparison of stresses obtained with FEM, Hertz theory and experimental method. It shows good level of agreement by all the method.

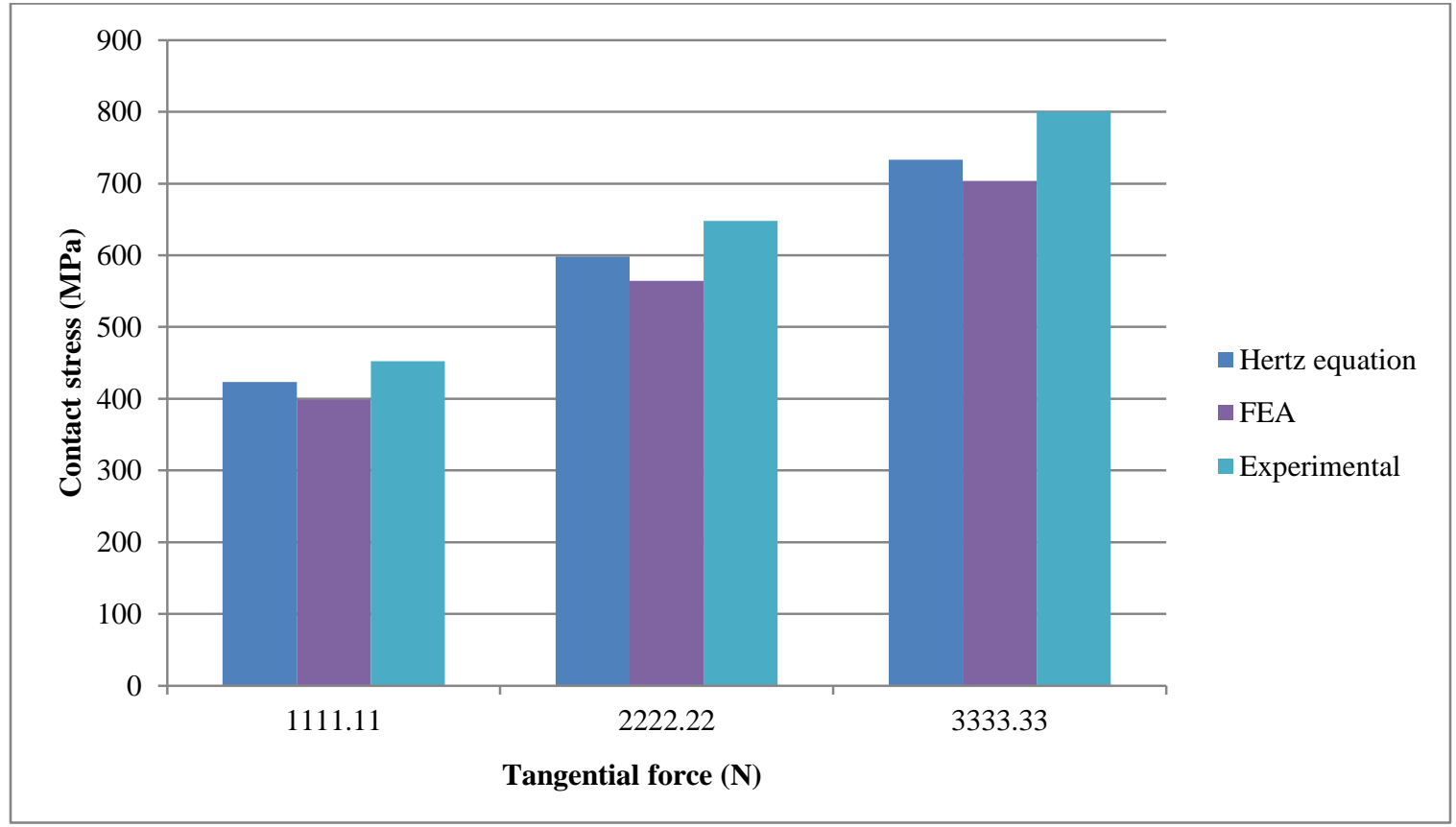

Figure 6 Plot of contact stress vs tangential force for steel gear pair using Hertz equation, FEA and Experimental 


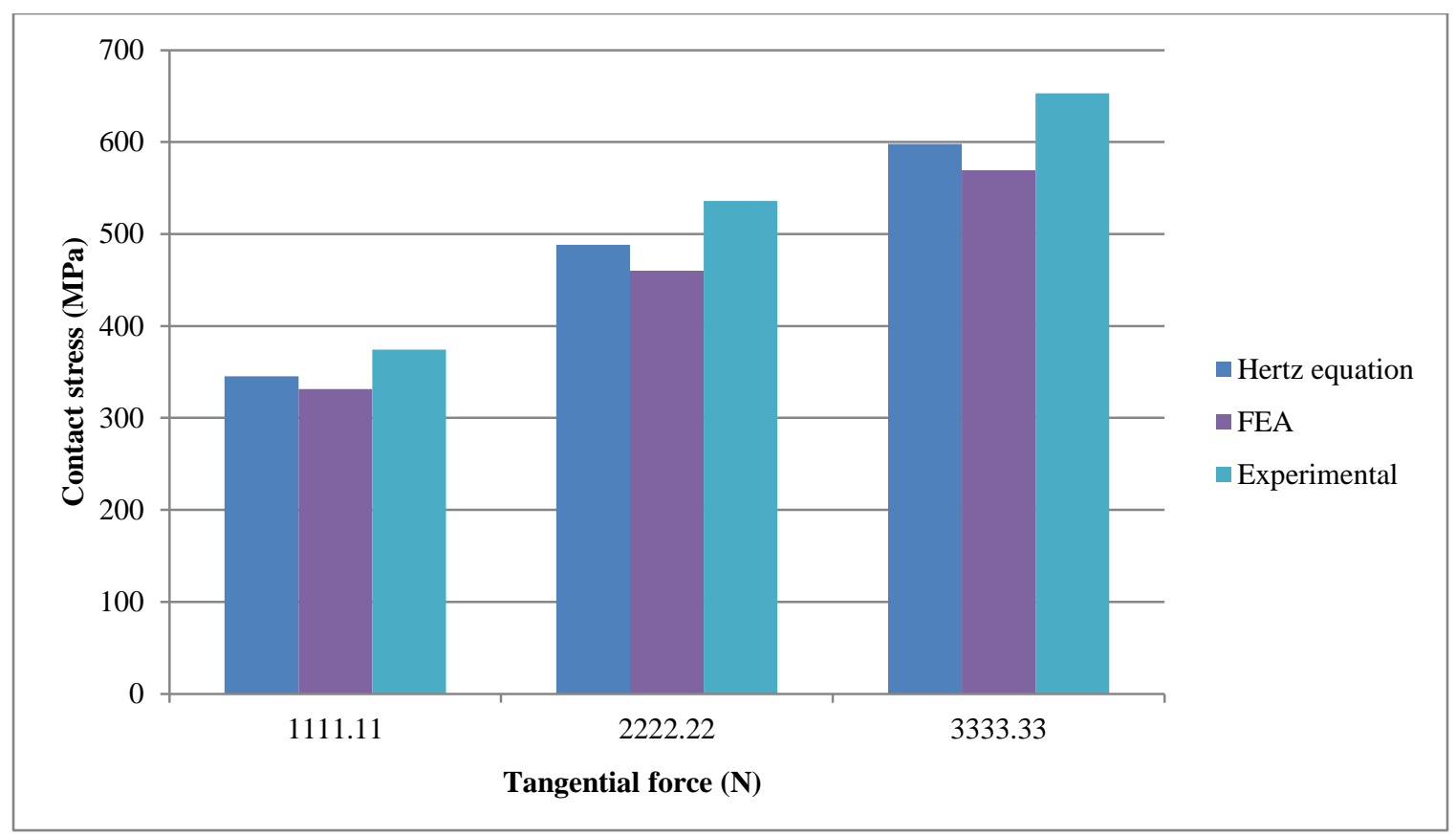

Figure 7 Plot of contact stress vs tangential force for composite gear pair using Hertz equation, FEA and Experimental

Percentage difference of stresses for steel and composite material using analytical method, FEA and experimental method is calculated. It is observed that the stresses are reduced by nearly $18 \%$ due to the use of composite material. Also the results are well within the difference of $10 \%$.

\section{Conclusions and future scope}

The following conclusions has been drawn from present study:

1. The density of composite gear is $2580 \mathrm{~kg} / \mathrm{m}^{3}$ as compared to $7850 \mathrm{Kg} / \mathrm{m}^{3}$ of steel gear. Thus the weight is reduced by almost 3 times by the use of composite gears.

2. The Aluminium silicon carbide and fly ash composite material is having less weight and more strength; It is very much useful in practical aerospace applications.

3. It was found that the results from both Hertz equation and FEA are comparable with the experimental strain gauge technique. The results are well within the difference of $10 \%$.

4. It was found that the results from Finite Element Analysis are comparable with the experimental Strain gauge technique. The results are well within the difference of $15 \%$.

5. It is observed that stress is reduced by nearly $18 \%$ due to the use of composite material.
6. These composites can be used for making power transmitting elements such as gears, which are subjected to continuous loading.

In future, this work can be extended by doing modal analysis of composite gears. Also vibration analysis can be done to check the effect of material. This work can be extended for analysis of bending strength of composite gear.

\section{Acknowledgment}

None.

\section{Conflicts of interest}

The authors have no conflicts of interest to declare.

\section{References}

[1] Pawar PB, Utpat AA. Development of aluminium based silicon carbide particulate metal matrix composite for spur gear. Procedia Materials Science. 2014; 6:1150-6.

[2] Pawar PB, Utpat AA. Analysis of composite material spur gear under static loading condition. Materials Today: Proceedings. 2015; 2(4-5):2968-74.

[3] Saravanan SD, Kumar MS. Effect of mechanical properties on rice husk ash reinforced aluminum alloy (AlSi10Mg) matrix composites. Procedia Engineering. 2013; 64:1505-13.

[4] Devi NC, Mahesh V, Selvaraj N. Mechanical characterization of aluminium silicon carbide 
Bakshe et al.

composite. International Journal of Applied Engineering Research. 2011; 1(4):793-9.

[5] Suragimath MP, Purohit DG. A study on mechanical properties of aluminium alloy (LM6) reinforced with $\mathrm{SiC}$ and fly Ash. IOSR Journal of Mechanical and Civil Engineering. 2013; 8(5):13-8.

[6] Hassan AR. Contact stress analysis of spur gear teeth pair. World Academy of Science, Engineering and Technology. 2009; 3(10):1279-84.

[7] Hwang SC, Lee JH, Lee DH, Han SH, Lee KH. Contact stress analysis for a pair of mating gears. Mathematical and Computer Modelling. 2013; 57(12):40-9.

[8] Tiwari SK, Joshi UK. Stress analysis of mating involute spur gear teeth. International Journal of Engineering Research \& Technology. 2012; 1(9):1-12.

[9] Khan MJ, Mangla A. Contact stress analysis of stainless steel spur gears using finite element analysis and comparison with theoretical results using hertz theory. International Journal of Engineering Research and Applications. 2015; 5(4):10-8.

[10] Quadri SA, Dhananjay RD. Contact stress analysis of involute spur gear under static loading. International Journal of Scientific Research Engineering \& Technology. 2015; 4(5):593-6.

[11] Kolambe CE, Barde DR. Study of helical gear analysis using FEA software. International Journal of Engineering Science and Computing. 2016; 6(3):213641.

[12] Rahate HP, Marne RA. Finite element analysis of composite spur gear for contact stress. International Journal of Advance Research in Science and Engineering. 2016; 5(1):231-6.

[13] Patil SS, Karuppanan S, Atanasovska I. Experimental measurement of strain and stress state at the contacting helical gear pairs. Measurement. 2016; 82:313-22.
[14] Jebur AK, Khan IA, Nath Y. Numerical and experimental dynamic contact of rotating spur gear. Modern Applied Science. 2011; 5(2):254-63.

[15] Chor PM, Pillai P. Spur gear contact stress analysis and stress reduction by experiment method. International Journal of Engineering Research and General Science. 2015; 3(3):126-35.

[16] Rahate HP, Marne RA. Contact stress analysis of composite spur gear using photo-stress method and finite element analysis. International Research Journal of Engineering and Technology. 2016; 3(7):540-5.

[17] Karaveer V, Mogrekar A, Joseph TP. Modeling and finite element analysis of spur gear. International Journal of Current Engineering and Technology. 2013; 3(5):2104-7.

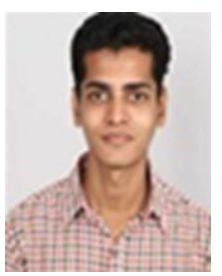

Mr. Bharat N. Bakshe is currently pursuing his Masters of Engineering from AISSMS COE, Pune. $\mathrm{He}$ completed his B.E. and Diploma in Mechanical Engineering from JTM COE, Faizpur from North Maharashtra University, Jalgaon.

Email: bakshebharat3@gmail.com

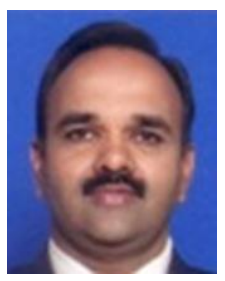

Mr. S. R. Patil is currently working as Assistant Professor in AISSMS COE, Pune. $\mathrm{He}$ is pursuing his $\mathrm{PhD}$ in Mechanical Engineering in research area of NVH. He completed Masters of Engineering in Mechanical with specialization in Design Engineering and B.E. in Mechanical Engineering from Pune University. 